\title{
ANÁLISE DA DENSIDADE ESPACIAL DE PATAMARES ESTRUTURAIS NO SETOR CENTRAL DO GEOMORFOSSÍTIO GUARITAS DO CAMAQUÃ - RS
}

\author{
Márlon Roxo Madeira $^{(\mathrm{a})}$; Gracieli Trentin $^{(\mathrm{b})}$; Adriano Luis Heck Simon ${ }^{(\mathrm{c})}$ \\ ${ }^{(a)}$ Bolsista de Iniciação Científica (CNPq), Departamento de Geografia, Universidade Federal de Pelotas, \\ marlonmadeira@hotmail.com \\ (b)Instituto de Oceanografia, Universidade Federal do Rio Grande, gracieli.trentin@furg.br \\ (c) Departamento de Geografia e Programa de Pós-graduação em Geografia, Universidade Federal de Pelotas, \\ adriano.simon@ufpel.edu.br
}

\section{Eixo: GEODIVERSIDADE, GEOARQUEOLOGIA E PATRIMÔNIO NATURAL}

\begin{abstract}
Resumo
Estudos sobre geodiversidade subsidiam as atividades de geoconservação e estabelecem formas de proteção dos recursos abióticos, auxiliando também na identificação das áreas que apresentam elementos da geodiversidade de interesse geomorfológico.A região das Guaritas do Camaquã (Rio Grande do Sul - Brasil), apresenta um conjunto de feições geomorfológicas com expressiva beleza cênica, potencial socioeconômico, importância científica, pedagógica e cultural. Neste sentido, este trabalho foi desenvolvido com o objetivo de analisar a densidade espacial dos patamares estruturais do setor central do geomorfossítio Guaritas do Camaquã. A partir do mapeamento geomorfológico de detalhe realizado nessa área, foi selecionado o plano de informação referente aos patamares estruturais, a fim de elaborar o mapa de densidade espacial destas feições na área em estudo. O mapa de densidade dos patamares estruturais possibilitou o refinamento de documentos mais complexos (mapa geomorfológico de detalhe) e explicitou a concentração dos patamares estruturais na porção centro-sul da área em estudo.
\end{abstract}

Palavras chave: geodiversidade; feições estruturais;análise espacial

\section{Introdução}

A disponibilidade de Sistemas de Informações Geográficas (SIG) torna possível compreender os fenômenos que ocorrem em diversas áreas do conhecimento, como por exemplo, questões relacionadas com o meio ambiente (CÂMARA 2002). Dentre as funcionalidades dos SIG's, a densidade espacial é utilizada por geógrafos e geomorfólogos, para descrever a distribuição espacial dos objetos deestudo, buscando realizar pesquisas que possibilitema identificação e análisede áreas para proteção, conservação, recuperação ou monitoramento ambiental. Estudos sobre densidade espacial das formas do relevo também possuem importante papel na promoção da geodiversidade e das áreas com significativo potencial paraa geoconservação. 
Nos últimos anos a geografia vem procurando abordar em seus estudos a importância da caracterização e proteção dos elementos da geodiversidade.Gray (2005) conceituaa geodiversidade como a variedade deambientes geológicos e geomorfológicos, compostos por rochas, minerais, fósseis, formas do relevo e processos físicos, capazes de modelar o relevo, servindo como base para a vida na Terra.

As formas do relevo estudadas pela geomorfologia fazem parte da geodiversidade e geralmente possuem grande importância por se tratar do elemento com maior expressão na paisagem (VIEIRA; SILVA, 2010).A geografia, ao analisar a ocorrência e a dinâmica espaço-temporal dos elementos naturais e socioeconômicos, vem contribuindo para o reconhecimento das áreas com maior concentração espacial dos elementos da geodiversidade, auxiliando na definição dos locais com maiores possibilidades de exploração, utilização e conservação (GRAY, 2005). Os estudos da geodiversidade subsidiamainda as atividades de geoconservação, estabelecendo formas de proteção dos recursos naturais abióticos, a partir das necessidades de cada área (PEREIRA, 2010).

Segundo Azevedo (2007), com o crescente interesse de pesquisadores sobre a necessidade de proteção dos elementos da geodiversidade, estratégias de geoconservação foram desenvolvidas, tendo como base o geopatrimônio reconhecido.Braga (2002) define o geopatrimônio como um conjunto de características geológicas, paisagens geomorfológicas, paleontológicas e mineralógicas, de significativo valor, e que possibilitam o entendimento e a interpretação da história geológica da Terra.

Segundo Borba (2011) o geopatrimônio consiste no conjunto de geossítios e geomorfossítios de um determinado território, reconhecidos e delimitados a partir de coordenadas geográficas bem definidas. Borba (2013) define ainda que estas áreas abrangem feições complexas e diversificadassob o ponto de vista geológico e geomorfológico.

A região das Guaritas do Camaquã, localizada na porção central do estado do Rio Grande do Sul, conjuga uma riqueza cênica ímpar, apresentandofeições com aparência de ruínas que descrevem a geomorfologia geral da área. Expõe também um relevo resultante de processos erosivos pluviaise fluviais agindo sobre o substrato sedimentar, com o domínio de morros parcialmente conectados, formando áreas semelhantes a guaritas ou casamatas (termos regionalmente utilizados para se referirem a espaços de proteção, utilizados por povos indígenas, populações afrodescendentes ou soldados durante a Revolução Farroupilha)(PAIM, 2010).Esta representatividade das feições ruiniformes levou Paim et al. (2010) a reconhecerem as Guaritas do Camaquã enquanto geossítio. Entretanto Panizza (2001), explica que geossítios onde as feições geomorfológicas expressam maior interesse devem ser reconhecidos como geomorfossítios.

Tendências mais recentes nos estudos da geodiversidade, dentro da perspectiva geomorfológica, têm utilizado metodologias e técnicas para auxiliar na identificação de áreas prioritárias para a preservação 


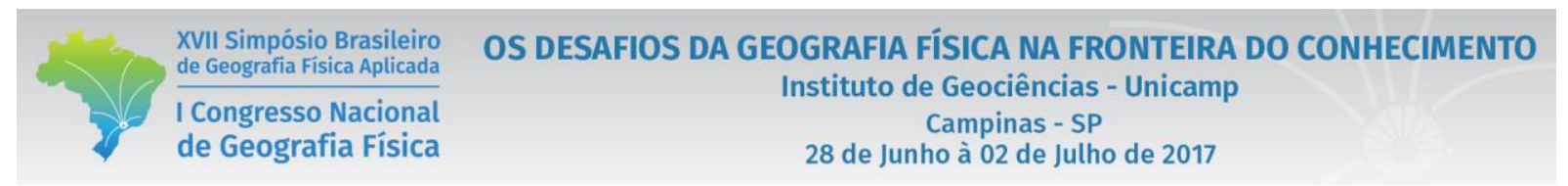

ambiental e/ou utilização científica, pedagógica e turística em geossítios e geomorfossítios(SANTOS, 2016). Nesse sentido, este trabalho foi desenvolvido com o objetivo de analisar a densidade espacial dos patamares estruturais do setor central do geomorfossítio Guaritas do Camaquã (Rio Grande do Sul Brasil). Essa análise permite definir onde há concentrações espaciais destas feiçõesem toda área do setor central. A identificação das áreascommaior ocorrência destas feições, por sua vez, possibilita a indicação de fragmentos espaciais com maior interesse para uso científico, pedagógico, cultural, entre outros.

\section{Caracterização da área em estudo}

O Setor Central do geomorfossítio Guaritas do Camaquã - RS encontra-se no limite territorial dos municípios de Caçapava do Sul e Santana da Boa Vista, localizado na região central do estado do Rio Grande do Sul (Figura 1).

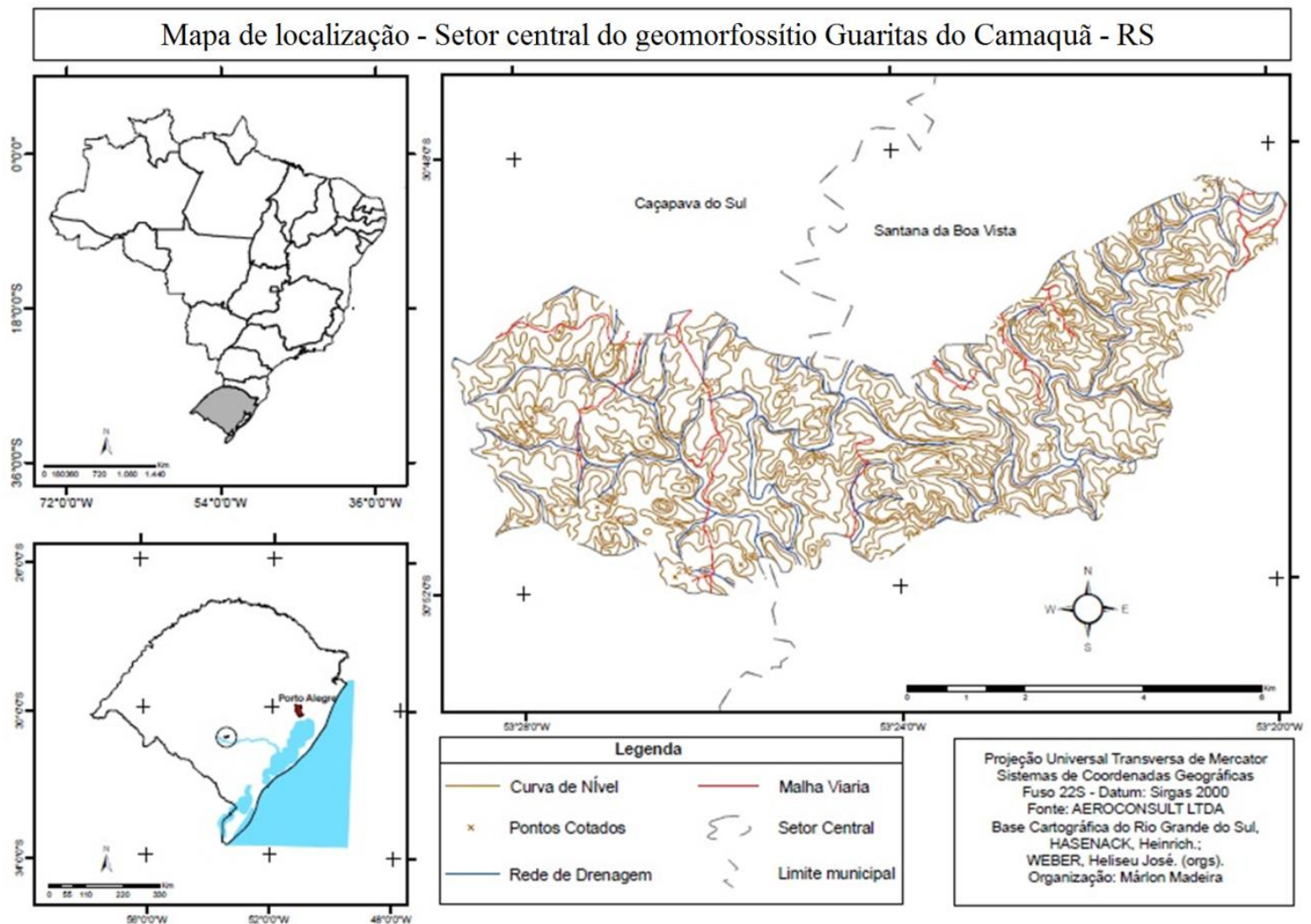

Figura 1 - Mapa de Localização do setor central do geomorfossítio Guaritas do Camaquã - RS.

A região das Guaritas do Camaquã compreende um grande conjunto de formas representativas sob os aspectos geológicos e geomorfológicos, seja pelos fatores dos processos naturais ou pela singular paisagem existente no local(PAIM, 2010). O clima temperado do tipo subtropical atuante no Rio Grande do Sul é predominante na região das Guaritas do Camaquã (ATLAS SÓCIO ECONÔMICO DO RIO GRANDE DO SUL, 2010). 
A Bacia Sedimentar do Camaquã - que abrange a área em estudo-apresenta uma espessa acumulação de sedimentos, formada por uma alternância de eventos predominantemente deposicionais (SANTOS, 2016). Sua evolução geológico-geomorfológica foi condicionada pela intercalação de climas secos e úmidos (TORRES et al., 2012).

Em função da diversidade doclima do Rio Grande do Sul, e por fazer parte da metade sul do Estado, a região das Guaritas do Camaquã insere-seno Bioma Pampa (IBGE, 2004). A cobertura vegetal original desse bioma identifica três tipos de formações vegetais:a campestre, a florestal, e a área de transição (MINISTÉRIO DO MEIO AMBIENTE, 2009). O processo de ocupação da área tem grande influência da colonização portuguesa, sendo as atividades econômicas baseadas na agricultura e na criação de gado (DEGRANDI, 2011).

\section{Metodologia}

A análise da densidade espacial dos patamares estruturais no setor central do geomorfossítio Guaritas do Camaquã foi realizada tomando como base a extensão (comprimento) das secções de linhas de patamares estruturais que foram identificadas no mapeamento geomorfológico de detalhe (1:50.000) elaborado por Santos (2016). A partir do mapeamento citado, foi selecionado o plano de informação referente aos patamares estruturais abrangidos pelo setor central do geomorfossítio. Esta seleção possibilitou a verificação inicial da presença mais generalizada e concentrada destas feições na área em estudo. Os patamares estruturais foram selecionados pois, a análise do mapa geomorfológico elaborado por Santos (2016) e as informações obtidas durante os trabalhos de campo na área evidenciaram que estas feições são as mais expressivas para a consolidação do relevo ruiniforme da área, apresentando aspectos importantes de beleza cênica, pedagógica, científica, cultural e socioeconômica, que conferem status de geomorfossítio à área em questão.

Aelaboração do mapa de densidadeespacial dos patamares estruturais ocorreu no ambiente do software Arc.Gis 10.3 (licença de uso do Laboratório de Estudos Aplicados em Geografia Física da UFPel), sendo utilizada a ferramenta Linedensity, presente na extensão SpatialAnalyst do software ArcGis 10.3. Aos resultados obtidos foram estabelecidas tonalidades diferentes de uma cor, representando a ocorrência dessa feição em valores de densidade que variam entre nulo (quando não há a existência de patamares estruturais), muito baixa, baixa, regular, alta e muito alta para cada comprimento de patamar estrutural identificado, de acordo com as orientações de Souza et. al (2013). Os valores correspondentes às classes foram definidos pelo método de intervalos iguais e se referem à concentração dos comprimentos destes patamares estruturais de acordo cos seguintes valores: Nulo (0); Muito Baixa (0,038 - 1,99 km); Baixa (2 - 3,94 km); Regular (3,95 - 5,88 km); Alta (5,89 - 7,83 km); Muito Alta (7,84 - 9,78 km). Segundo 


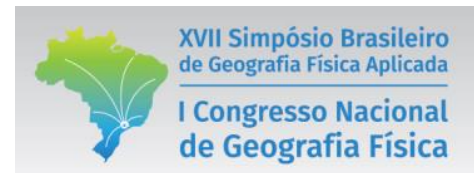
OS DESAFIOS DA GEOGRAFIA FÍSICA NA FRONTEIRA DO CONHECIMENTO
Instituto de Geociências - Unicamp
Campinas - SP
28 de Junho à 02 de Julho de 2017

Souza et al., (2013) em uma análise de densidade espacial, quando for detectada uma tonalidade de cor mais intensa, ocorre a concentração elevada do objeto de estudo, por este motivo ocorre uma graduação de cores mais claras para cores mais escuras na medida em que existe uma maior concentração dos comprimentos dos patamares estruturais no setor central do geomorfossítio das Guaritas do Camaquã RS.

Por fim, ocorreu a relação das informações sobre a densidade espacial dos patamares estruturais com a localização espacial das instalações agrícolas presentes na área e com as principais estradas que conectam estas instalações agrícolas com vilas e áreas urbanizadas. Esta relação ocorreu para que se pudesse compreender a proximidade das feições estruturais com vias de acesso e propriedades rurais.

\section{Resultados}

Dispondo como base a classificação quantitativa de comprimento de linha dos patamares estruturais, os resultados obtidos a partir da elaboração do mapa de densidade espacial (Figura 2), mostram que a extensão "muito alta" representada pela tonalidade mais escura da cor laranja, caracteriza uma maior concentração de comprimento de linha dos patamares estruturaisna porção centro-sul da área em estudo.

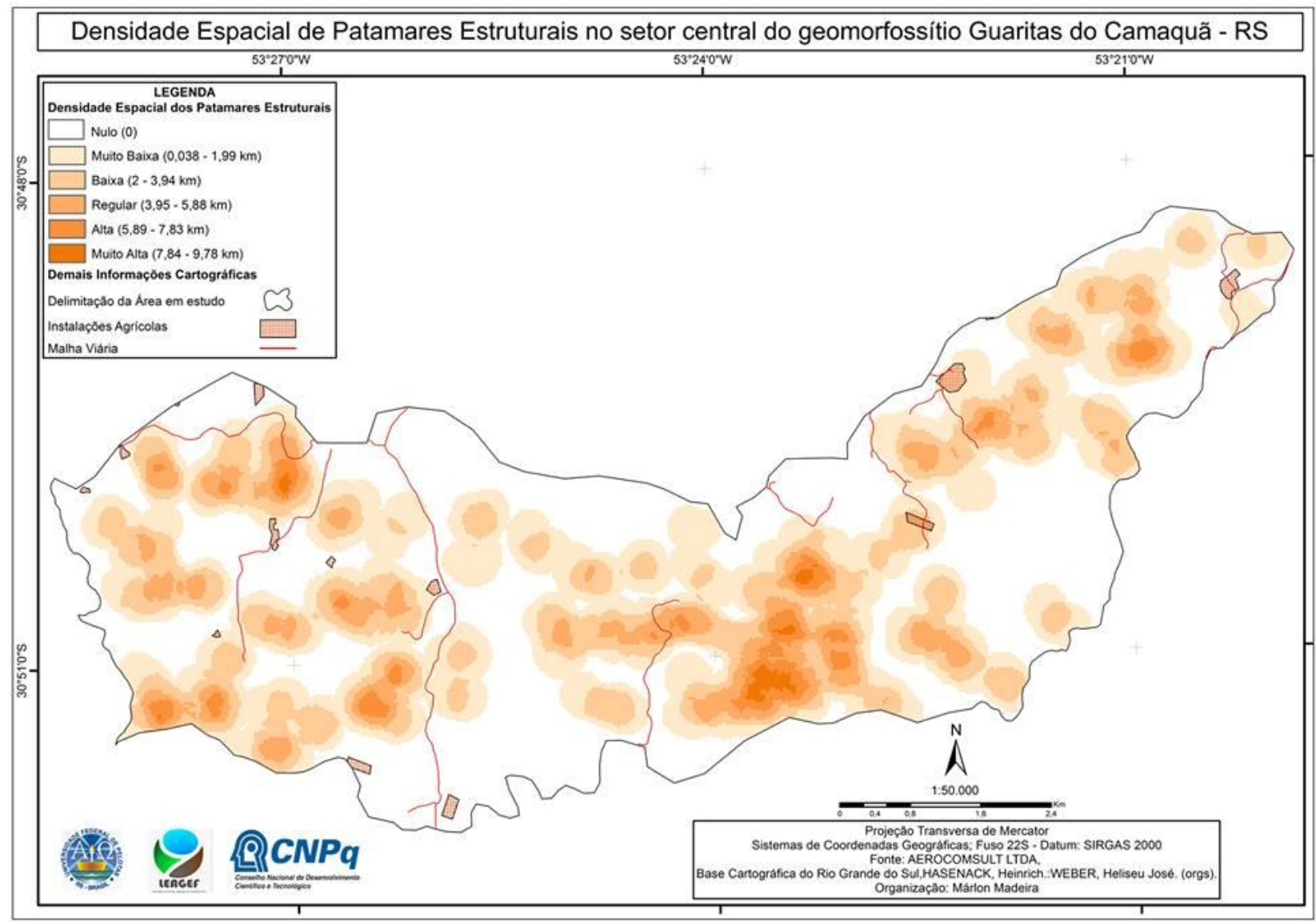

Figura 2 -Densidade Espacial de Patamares estruturais no setor central do geomorfossítio Guaritas do Camaquã. 
Nesta área foram encontradas concentrações de patamares estruturais amplamente conectados, que chegam a possuir extensões de até nove quilômetros (Figura 3). A porção centro-sul, por possuir maiores evidências desta feição geomorfológica (patamar estrutural), acaba por contribuir noestabelecimento da beleza cênica local, tornando-se uma área de relevante interesse geomorfológico. Câmara et al., (2002) cita que a análise da densidade espacial permite descrever a distribuição das variáveis de estudo, sendo capaz de identificar a existência de padrões na distribuição espacial. Nos limites leste e oeste do setor central foram verificados valores altos de densidade seguidos de valores que vão de regular a baixo. Consequentemente, nos trabalhos de campo realizados no limite oeste, foram identificados patamares estruturais bastante desconectados em função da erosão plúvio-erosiva (Figura 4), ocasionando a diminuição da concentração dos patamares estruturais dessa área.

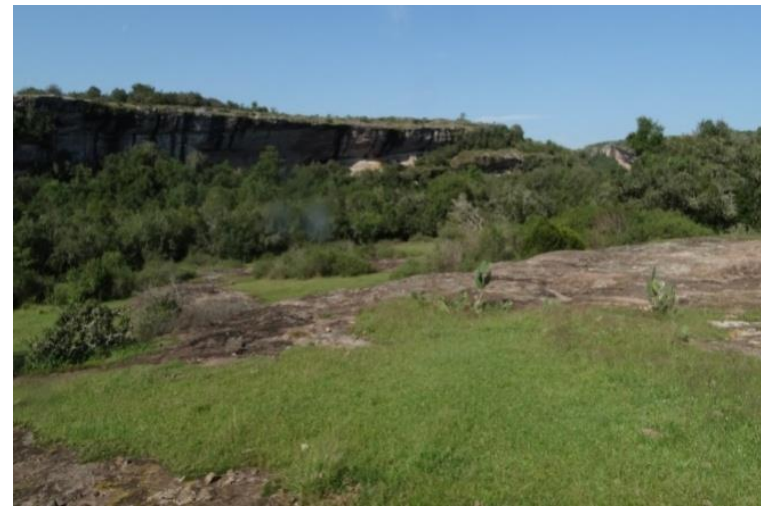

Figura 3 - Registro de campo em área com densidade alta e muito alta de patamares estruturais.

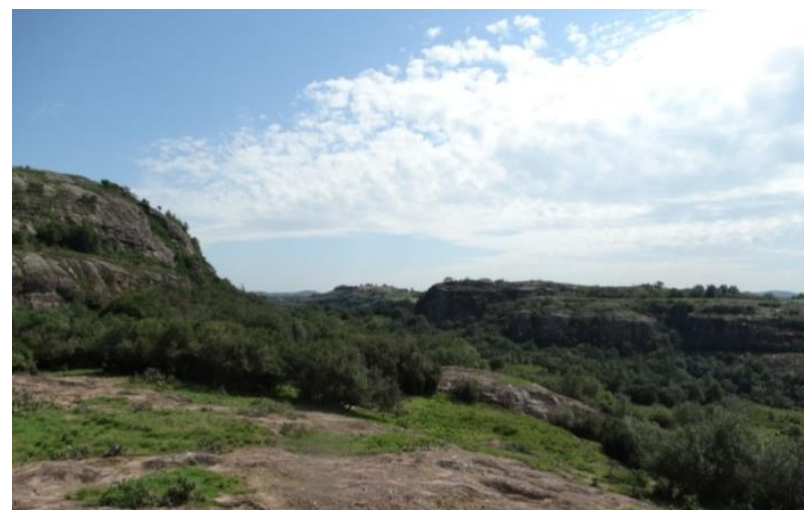

Figura 4 - Registro de campo em área com densidade muito baixa e baixa de patamares estruturais.

Santos (2016) afirma que a sobreposição dos dados entre os patamares estruturais e o uso da terra, se torna fundamental, ao passo que, a falta de políticas públicas somada ao desconhecimento sobre os aspectos e potenciais da geodiversidade, podem atuar na degradação dos elementos geológicos-geomorfológicos, possibilitando a identificação de áreas onde ocorram impactos diretos e indiretos sobre a geodiversidade, e assim, contribuindo com iniciativas de geoconservação no geomorfossítio Guaritas do Camaquã.

Conforme verificado no mapa de densidade (Figura 2), a malha viária sofre grande influência das instalações agrícolas presentes na área em estudo. Essas áreas se fixam em declividades baixas e se referem aos cultivos de subsistência atrelados às propriedades ruraisque tem na pecuária sua principal fonte de renda (SANTOS, 2016). Destaca-se que a maior parte das instalações agrícolas se encontram afastadas dos patamares estruturais, favorecendo a preservação da geodiversidade. Outra questão 
importante a ser destacada é a existência de vias de acesso próximas às áreas com maiores densidades espaciais dos patamares estruturais, fato que possibilita a chegada até estes geomonumentos a partir de trilhas e inviabiliza a chegada com veículos (questão considerada positiva para a manutenção das propriedades bióticas e abióticas da área).

\section{Considerações Finais}

A análise da densidade espacial dos patamares estruturais do setor central do geomorfossítio das Guaritas do Camaquã possibilitou identificar que na porção centro-sul do setor central ocorrem as maiores concentrações destas feições.O mapa de densidade espacial,viabilizou ainda uma melhor leitura e interpretação em comparação às representações lineares do mapa geomorfológico de detalhe elaborado por Santos (2016). Dessa forma, acredita-se que este estudo inicial sobre a densidade espacial de feições geomorfológicas com maior expressão na paisagem do geomorfossítio deva ser estendido para as demais feições mapeadas, a fim de que se possa estabelecer um mapa de densidade espacial que integre todas as formas do relevo com representatividade na área de estudo.

\section{REFERÊNCIAS}

Atlas socioeconômico do Rio Grande do Sul. Disponível em: <www.scp.rs.gov.br/atlas〉.

AZEVEDO, U. R. Patrimônio Geológico e geoconservação no Quadrilátero Ferrífero, Minas Gerais: potencial para a criação de um geoparque da Unesco. 2007. 211f. Tese (Doutorado) - Instituto de Geociências, Universidade Federal de Minas Gerais, Belo Horizonte, 2007.

BORBA, A. W. Geodiversidade e geopatrimônio como bases para estratégiasde geoconservação: conceitos, abordagens, métodos de avaliação eaplicabilidade no contexto do Estado do Rio Grande do Sul. Pesquisa emGeociências, Porto Alegre, v. 38, n. 1, p. 3 - 14, 2011.

BORBA, A. W. et al. Inventário e avaliação quantitativa de geossítios: exemplode aplicação ao patrimônio geológico do município de Caçapava do Sul (RS,Brasil). Pesquisas em Geociências, v. 40 (3), p. 275-294, set./dez. 2013

CÂMARA, G. et al. "Análise espacial e geoprocessamento". Análise espacial de dados geográficos 2 (2002).

CUNHA, C. M. L. A cartografia do relevo no contexto da gestão ambiental. 2001. 128f. Tese (Doutorado em Geociências e Meio Ambiente) - Instituto de Geociências e Ciências Exatas, Universidade Estadual Paulista, Rio Claro, 2001.

DEGRANDI, S. M. Ecoturismo e Interpretação da Paisagem no Alto do Camaquã/RS: uma alternativa para o (des)envolvimento local? 2011. 197f. Dissertação (Mestrado em Geografia e Geociências) - Universidade Federal de Santa Maria, Santa Maria, 2011.

GRAY, M. Geodiversity\&Geoconservation, GeodiversityandGeoconservation: What, Why, andHow?, London, v. 3, n. 3, p. 4-12, 2005.

HASENACK, H.; WEBER, E. (orgs.). Base cartográfica vetorial contínua do Rio Grande do Sul - escala 1:50.000. Porto Alegre: UFRGS-IB-Centro de Ecologia. 2010. 1 DVD-ROM (Série Geoprocessamento, 3).

PAIM, P. S. G.; FALlGATTER, C.; SILVEIRA, A. S. Guaritas do Camaquã, RS - Exuberante cenário com formações geológicas de grande interesse didático e turístico. In: Winge, M.; Schobbenhaus, C.; Souza. C.R.G.; Fernandes, A.C.S.; Berbert-Born, M.; Sallunu Filho, W.; Queiroz, E.T.. (Org.). Sítios Geológicos e Paleontológicos do Brasil. 1ed.Brasília: Departamento nacional de Produção Mineral, 2010, v. III, p. 1-13. 


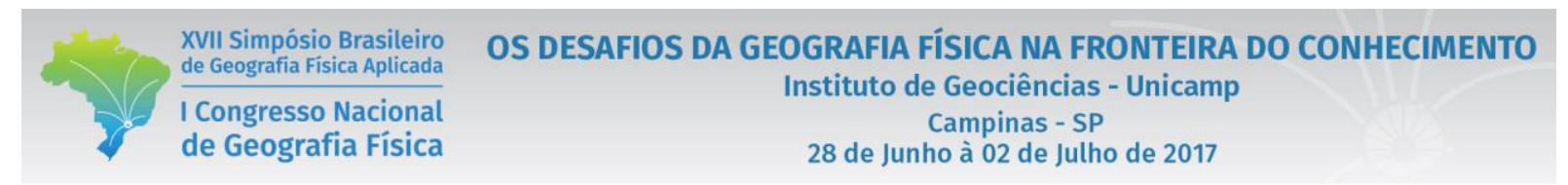

PEREIRA, R. G. F. A. Geoconservação e Desenvolvimento Sustentável na Chapada Diamantina (Bahia - Brasil). 2010. 225f. Tese (doutorado) - Escola de Ciências, Universidade do Minho, Braga, Portugal, 2010.

REYNARD, E.; PANIZZA, M. Geomorphosites: definition, assessmentandmapping, Géomorphologie: relief, processus, environnement, vol. 11 - $\mathrm{n}^{\circ} 3$ |2005, 177-180.

SANTOS, F.C.A. Mapeamento Geomorfológico do Geossítio das Guaritas do Camaquã/RS: Subsídios à Geoconservação.Dissertação (Mestrado em Geografia) - Universidade Federal de Pelotas, Pelotas, 2016.

SOUZA, NP, et al. "Aplicação do Estimador de Densidade kernel em Unidades de Conservação na Bacia do Rio São Francisco para análise de focos de desmatamento e focos de calor." XVI SIMPÓSIO BRASILEIRO DE SENSORIAMENTO REMOTO, Foz do Iguaçu, PR (2013).

TORRES, F. T. P.; NETO, R. M.; MENEZES, S. O. M. Introdução à Geomorfologia. São Paulo: Cengage Learning, 2012.

VIEIRA, A, C. ; SILVA, D, R, A. Geodiversidade do Estado do Rio Grande do Sul, Porto Alegre: CPRM, 2010. 